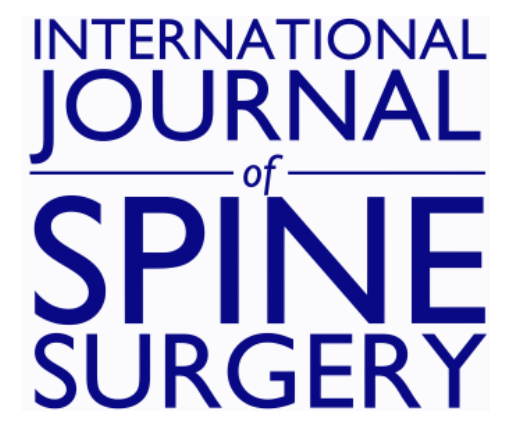

\title{
Analysis of Postoperative Thoracolumbar Spine Infections in a Prospective Randomized Controlled Trial Using the Centers for Disease Control Surgical Site Infection Criteria
}

Shearwood McClelland III, Richelle C. Takemoto, Baron S. Lonner, Tate M. Andres, Justin J. Park, Pedro A. Ricart-Hoffiz, John A. Bendo, Jeffrey A. Goldstein, Jeffrey M. Spivak and Thomas J. Errico

Int J Spine Surg 2016, 10 ()

doi: https://doi.org/10.14444/3014

http://ijssurgery.com/content/10/14

This information is current as of April 25, 2023.

Email Alerts Receive free email-alerts when new articles cite this article. Sign up at:

http://ijssurgery.com/alerts

The International Journal of Sping Surgerhth://ijssurgery.com/ by guest on April 25, 2C 2397 Waterbury Circle, Suite 1,

Aurora, IL 60504, Phone: +1-630-375-1432

(C) 2016 ISASS. All Rights Reserved. 


\section{Analysis of Postoperative Thoracolumbar Spine Infections in a Prospective Randomized Controlled Trial Using the Centers for Disease Control Surgical Site Infection Criteria}

Shearwood McClelland III, MD, ${ }^{1}$ Richelle C. Takemoto, MD, ${ }^{1}$ Baron S. Lonner, MD, ${ }^{2}$ Tate M. Andres, BS, ${ }^{1}$ Justin J. Park, MD, ${ }^{1}$ Pedro A. Ricart-Hoffiz, $M D,{ }^{1}$ John A. Bendo, MD, ${ }^{1}$ Jeffrey A. Goldstein, MD, ${ }^{1}$ Jeffrey M. Spivak, MD, ${ }^{1}$ Thomas J. Errico, $M D^{1}$

${ }^{1}$ Division of Spine Surgery, Hospital for Joint Diseases, NYU Langone Medical Center, New York, NY, 2 Department of Orthopaedics, Mount Sinai Beth Israel, New York, $N Y$

\section{Abstract}

Introduction

Wound infections following spinal surgery place a high toll on both the patient and the healthcare system. Although several large series studies have examined the incidence and distribution of spinal wound infection, the applicability of these studies varies greatly since nearly every study is either retrospective and/or lacks standard inclusion criteria for defining surgical site infection. To address this void, we present results from prospectively gathered thoracolumbar spine surgery data for which the Centers for Disease Control (CDC) criteria were stringently applied to define a surgical site infection (SSI).

\section{Methods}

A prospective randomized trial of 314 patients who underwent multilevel thoracolumbar spinal surgery with instrumentation followed by postoperative drain placement was completed (Takemoto et al., 2015). The trial consisted of two antibiotic arms: one for 24-hours, and the other for the duration of the drain; no differences were found between the arms. All infections meeting CDC criteria for SSI were included.

Results

A total of 40 infections met CDC criteria for SSI, for an overall incidence of $12.7 \%$. Of these, 20 (50\%) were culture-positive. The most common organism was Staphylococcus aureus (4 total: methicillin-sensitive=2; methicillin-resistant=2), followed by coagulase-negative Staphylococcus (3 cases), Propionibacterium acnes and Escherichia coli ( 2 cases each). Six infections grew multiple organisms, most commonly involving coagulasenegative staphylococcus and enterococcus.

\section{Conclusions}

Our findings indicate that thoracolumbar SSI occurs at the higher end of the range cited in the literature (2-13\%), which is largely based on retrospective data not subjected to the inclusivity of SSI as defined by the CDC. The three most common organisms in our analysis (S. aureus, P. acnes, E. coli) are consistent with previous reports. Staphylococcus aureus continues to be the most common causative organism and continued vigilance and searching for preventive measures need to be a high priority. This study provides Level I evidence.

KEYWORDS: THORACOLUMBAR SPINE SURGERY, PROSPECTIVE DATA COLLECTION, SURGICAL SITE INFECTION, CENTERS FOR DISEASE CONTROL CRITERIA, STAPHYLOCOCCUS AUREUS, PROPIONIBACTERIUM ACNES

VOLUME 10 ARTICLE 14 DOI: 10.14444/3014

\section{Introduction}

Wound infections following spinal surgery are fraught with morbidity, placing a high toll on both the patient and the healthcare system. ${ }^{1-3}$ Although several large series studies have examined the incidence and distribution of spinal would infection, the applicability of these studies varies greatly since nearly Downloaded from http://ijssurgery.com/ by guest on April 25, 2023 every study is either retrospective and/or lacks standard inclusion criteria for defining surgical site infection. ${ }^{4-7}$ To address this void, we present results from prospectively gathered thoracolumbar spine surgery data for which the Centers for Disease Control (CDC) criteria were stringently applied to define a surgical site infection (SSI). ${ }^{8-9}$ 


\section{Methods}

The data source for this study was a prospective randomized comparative study in which patients with a deformity or degenerative condition of the thoracic and/or lumbar spine requiring spinal surgery with a postoperative drain were randomized to two antibiotic-regimen arms: one for 24 hours, and the other for the duration of drain placement. ${ }^{9}$ Two hundred and fifty-six received cefazolin, while 13 received vancomycin and the remaining 45 received clindamycin. ${ }^{9}$ Patients were enrolled from September 2008 until February 2011; a total of 314 patients met criteria for randomization and the study was approved by our institution's Institutional Review Board as previously described. ${ }^{9}$ All surgeries were performed by fellowship-trained orthopaedic spine surgeons, and all data was prospectively collected postoperatively. All patients had a minimum of oneyear of postoperative follow-up;

Surgical site infection (SSI) was defined according to CDC criteria and was made by an attending physician specializing either in orthopaedic spinal surgery or infectious disease. As per CDC criteria, SSI was defined as an infection occurring within one year postoperatively that was related to the operative procedure and involved the skin incision, fascia, or muscle layers in a patient with at least one of the following: organisms isolated from an aseptically obtained culture of tissue or fluid, purulent drainage from a drain which had been placed into the surgical space via a stab wound, direct examination of an abscess or other evidence of infection involving the surgical space (i.e. during histological examination, radiographic examination, or during reoperation), or the diagnosis of SSI by an attending physician. ${ }^{10}$ SSI was used as the primary endpoint; there were no alterations of trial outcome measures after the trial began. ${ }^{9}$

\section{Results}

A total of 40 infections met CDC criteria for SSI, for an overall incidence of $12.7 \%$. Of these, 20 (50\%) grew out organisms. The most common organism was Staphylococcus aureus (4 total: methicillinsensitive $=2$; methicillin-resistant $=2$ ), followed by coagulase-negative Staphylococcus (3 cases), Propionibacterium acnes and Escherichia coli (each with 2 total) (Table 1). Six of these 20 infections grew multiple organisms, which most commonly involved coagulase-negative staphylococcus and enterococcus.

Of the 20 SSIs that grew out organisms on culture, 13 were superficial, six were deep, and one was both superficial and deep (Table 1). Five of these infections were delayed (occurring later than 30 days after surgery), 13 occurred acutely (defined as within 30 days following surgery), and two were classified as both acute and delayed (Table 1).

Five of the 40 infections required operative revision; only one of these had an organism that grew out on culture. 17 infections required subsequent incision and drainage; only two infections required both revision and I\&D (neither of these grew out organisms on culture). The antibiotic route and I\&D distribution among infections with culture-positive organisms can be found in Table 1.37 of the 40 infections (93\%) involved operative fusion. Exactly half of the 40 infections occurred in revision cases.

\section{Discussion}

Despite the preponderance with which operative management of the spine occurs, there have been relatively few reports in the literature examining the incidence of SSI in thoracolumbar spine surgery. Given the completion of our recent trial examining this issue, we believed that an investigation into the type of infections encountered in our study would provide a significant contribution to the literature given how few reports of SSI are collected prospectively and with rigorous adherence to CDC SSI criteria.

The established range of SSI in thoracolumbar spine surgery is $2-13 \%$ based on the existing literature. ${ }^{1-2,11-13}$ Some centers have used prophylactic vancomycin powder intraoperatively in an attempt to lower infection rates, with mixed results. ${ }^{14-16}$ None of the $314 \mathrm{pa}-$ tients in our study were exposed to prophylactic vancomycin powder intraoperatively.

The importance of this study's reliance on the CDC definition of SSI cannot be overstated, as reported 
SSI rates have been shown to vary greatly when a standard SSI definition is not used. ${ }^{17-18}$ Despite our infection rates being subjected to the inclusiveness of the CDC SSI definition, our overall infection rate of 12.7\% falls within that of the published literature, which is based largely on nonstandard SSI criteria which would be expected to artificially lower their overall infection rates. It is our hope that our findings will encourage others to publish their own infection data without fear of infection rates being (falsely) presumed to be abnormally high in comparison with literature not relying on strict SSI definitions. Encouraging is the recent publication of a prospectively gathered spinal SSI population meeting CDC criteria, although those patients did not have the same increased risk as our patient population of universally having an intraoperative drain placed. ${ }^{19}$

An interesting finding was the prevalence of $\mathrm{P}$. acnes, which occurred as frequently as MSSA and MRSA in our series and comprised $10 \%$ of the culturepositive organisms found in our series (Table 1); this incidence is consistent with recent literature. ${ }^{20-21}$ Also consistent with the majority of the postoperative spinal infection literature was that our most common causative organism was S. aureus (comprising 20\% of

Table 1. Culture-positive surgical site infections following thoracolumbar spine surgery with drain placement

\begin{tabular}{|c|c|c|c|c|c|}
\hline Organism & $\begin{array}{l}\text { Depth of } \\
\text { infection }\end{array}$ & $\begin{array}{l}\text { Timing of } \\
\text { Infection }\end{array}$ & $\begin{array}{l}\text { Antibiotic Treatment } \\
\text { Route }\end{array}$ & $\begin{array}{l}\text { Revision } \\
\text { Performed? }\end{array}$ & $\begin{array}{l}\text { Incision and Drainage } \\
\text { Performed? }\end{array}$ \\
\hline MSSA & Superficial & Delayed & IV & No & No \\
\hline MSSA & Deep & Acute \& Delayed & PO \& IV & No & Yes \\
\hline MRSA & Deep & Acute & PO \& IV & No & Yes \\
\hline MRSA & Deep & Delayed & PO \& IV & No & Yes \\
\hline CNS & Superficial & Acute & PO \& IV & No & No \\
\hline CNS & Superficial & Acute & $\mathrm{PO}$ & No & No \\
\hline $\mathrm{CNS}$ & Superficial & Acute & PO \& IV & No & Yes \\
\hline Propionibacterium acnes & Superficial & Acute & $\mathrm{PO}$ & No & No \\
\hline Propionibacterium acnes & Superficial & Acute \& Delayed & $\mathrm{PO}$ & No & Yes \\
\hline Escherichia coli & Superficial & Acute & $\mathrm{PO}$ & No & Yes \\
\hline Escherichia coli & Deep & Acute & IV & No & Yes \\
\hline Enterococcus & Superficial & Acute & PO \& IV & No & Yes \\
\hline Enterobacter & Superficial & Acute & PO \& IV & No & Yes \\
\hline Klebsiella & $\begin{array}{l}\text { Superficial and } \\
\text { Deep }\end{array}$ & Acute & IV & No & Yes \\
\hline Polymicrobial + CNS & Deep & Acute & PO \& IV & No & Yes \\
\hline Polymicrobial + Enterococcus & Superficial & Acute & PO \& IV & No & Yes \\
\hline Enterococcus + Candida albicans & Deep & Acute & IV & No & Yes \\
\hline $\begin{array}{l}\text { Gram-negative rods }+ \text { Klebsiella }+ \\
\text { Enterococcus }\end{array}$ & Superficial & Delayed & PO \& IV & No & No \\
\hline Klebsiella + CNS & Superficial & Delayed & $\mathrm{PO}$ & Yes & No \\
\hline Pseudomonas + CNS & Superficial & Delayed & IV & No & No \\
\hline
\end{tabular}

MSSA = Methicilin-sensitive Staphylococcus aureus; MRSA = Methicilin-resistant Staphylococcus aureus; CNS = Coagulase-negative Staphylococcus; Acute = within 30 days of surgery; Delayed = after 30 days following surgery; Acute $\mathcal{E}$ Delayed = one acute infection + one delayed infection in the same patient; IV = intravenous; $\mathrm{PO}=$ by mouth. 
the culture-positive organisms in our study) with coagulase-negative staphylococcus and E. coli comprising a significant representation as well..$^{19,22-25}$

In conclusion our series, which represents one of the first analyses of prospectively collected thoracolumbar postoperative spine infections meeting CDC criteria, revealed an overall infection incidence of $12.7 \%$, of which only $50 \%$ grew organisms on culture. The three most common organisms in our analysis (S. aureus, P. acnes, E. coli) are consistent with previous reports. Our findings indicate that thoracolumbar SSI occurs at the higher end of the range cited in the literature (2-13\%), which is largely based on retrospective data not subjected to the inclusivity of SSI as defined by the CDC. Staphylococcus aureus continues to be the most common causative organism and continued vigilance and searching for preventive measures need to be a high priority. Further studies of prospectively collected data using a larger sample size will be needed to better gauge the true incidence and most common causes of thoracolumbar SSI.

\section{References}

1. Glassman SD, Dimar JR, Puno RM, Johnson JR. Salvage of instrumental lumbar fusions complicated by surgical wound infection. Spine (Phila Pa 1976). 1996;21(18):2163-2169.

2. Whitehouse JD, Friedman ND, Kirkland KB, Richardson WJ, Sexton DJ. The impact of surgicalsite infections following orthopedic surgery at a community hospital and a university hospital: adverse quality of life, excess length of stay, and extra cost. Infect Control Hosp Epidemiol. 2002;23(4):183-189.

3. Fang A, Hu SS, Endres N, Bradford DS. Risk factors for infection after spinal surgery. Spine (Phila Pa 1976). 2005;30(12):1460-1465.

4. Stambough JL, Beringer D. Postoperative wound infections complicating adult spine surgery. J Spinal Disord. 1992;5(3):277-285.

5. Weinstein MA, McCabe JP, Cammisa FP Jr. Postoperative spinal wound infection: a review of 2,391 consecutive index procedures. J Spinal Disord. 2000;13(5):422-426.

6. Rechtine GR, Bono PL, Cahill D, Bolesta MJ, Chrin AM. Postoperative wound infection after in- strumentation of thoracic and lumbar fractures. $J$ Orthop Trauma. 2001;15(8):566-569.

7. Schimmel JJ, Horsting PP, de Kleuver M, Wonders G, van Limbeek J. Risk factors for deep surgical site infections after spinal fusion. Eur Spine J. 2010;19(10):1711-1719.

8. Nota SP, Braun Y, Ring D, Schwab JH. Incidence of surgical site infection after spine surgery: what is the impact of the definition of infection? Clin Orthop Relat Res. 2015;473(5):1612-1619.

9. Takemoto RC, Lonner B, Andres T, Park J, Ricart-Hoffiz P, Bendo J, Goldstein J, Spivak J, Errico T. Appropriateness of Twenty-four-Hour Antibiotic Prophylaxis After Spinal Surgery in Which a Drain Is Utilized: A Prospective Randomized Study. J Bone Joint Surg Am. 2015;97(12):979-986.

10. Horan TC, Gaynes RP, Martone WJ, Jarvis WR, Emori TG. CDC definitions of nosocomial surgical site infections, 1992: a modification of CDC definitions of surgical wound infections. Infect Control Hosp Epidemiol. 1992;13(10):606-608.

11. Mok JM, Guillaume TJ, Talu U, Berven SH, Deviren V, Kroeber M, Bradford DS, Hu SS. Clinical outcome of deep wound infection after instrumented posterior spinal fusion: a matched cohort analysis.Spine (Phila Pa 1976). 2009;34(6):578-583.

12. Koutsoumbelis $S$, Hughes AP, Girardi FP, Cammisa FP Jr, Finerty EA, Nguyen JT, Gausden E, Sama AA. Risk factors for postoperative infection following posterior lumbar instrumented arthrodesis. J Bone Joint Surg Am. 2011;93(17):1627-1633.

13. Bišćević $M$, Bišćević $S$, Ljuca F, Smrke BU, Krupić F, Habul Ć. Postoperative infections after posterior spondylodesis of thoracic and lumbal spine. Surgical spine infections. Psychiatr Danub. 2014;26 Suppl 2:382-386.

14. Molinari RW, Khera OA, Molinari WJ 3rd. Prophylactic intraoperative powdered vancomycin and postoperative deep spinal wound infection: 1,512 consecutive surgical cases over a 6-year period. Eur Spine J. 2012;21 Suppl 4:S476-482.

15. Tubaki VR, Rajasekaran S, Shetty AP. Effects of using intravenous antibiotic only versus local intrawound vancomycin antibiotic powder application in addition to intravenous antibiotics on postoperative infection in spine surgery in 907 patients. Spine (Phila Pa 1976). 2013;38(25):2149-2155. 
16. Ghobrial GM, Thakkar V, Andrews E, Lang M, Chitale A, Oppenlander ME, Maulucci CM, Sharan AD, Heller J, Harrop JS, Jallo J, Prasad S. Intraoperative vancomycin use in spinal surgery: single institution experience and microbial trends. Spine (Phila Pa 1976). 2014;39(7):550-555.

17. Ehrenkranz NJ, Richter EI, Phillips PM, Shultz JM. An apparent excess of operative site infections: analyses to evaluate false-positive diagnoses. Infect Control Hosp Epidemiol. 1995;16(12):712-716.

18. Taylor G, McKenzie M, Kirkland T, Wiens R. Effect of surgeon's diagnosis on surgical wound infection rates. Am J Infect Control 1990;18(5):295-299. 19. Durkin MJ, Dicks KV, Baker AW, Moehring RW, Chen LF, Sexton DJ, Lewis SS, Anderson DJ. Postoperative infection in spine surgery: does the month matter? J Neurosurg Spine.

2015;23(1):128-134.

20. Maruo K, Berven SH. Outcome and treatment of postoperative spine surgical site infections: predictors of treatment success and failure. JOrthop Sci. 2014;19(3):398-404.

21. Haidar R, Najjar M, Der Boghossian A, Tabbarah $\mathrm{Z}$. Propionibacterium acnes causing delayed postoperative spine infection: review. Scand J Infect Dis. 2010;42(6-7):405-411.

22. Abdul-Jabbar A, Berven SH, Hu SS, Chou D, Mummaneni PV, Takemoto S, Ames C, Deviren V, Tay B, Weinstein P, Burch S, Liu C. Surgical site infections in spine surgery: identification of microbiologic and surgical characteristics in 239 cases. Spine (Phila Pa 1976). 2013;38(22):E1425-1431.

23. Chen $\mathrm{SH}$, Lee $\mathrm{CH}$, Huang KC, Hsieh PH, Tsai
SY. Postoperative wound infection after posterior spinal instrumentation: analysis of long-term treatment outcomes. Eur Spine J. 2015;24(3):561-570. 24. Lim S, Edelstein AI, Patel AA, Kim BD, Kim JY. Risk Factors for Postoperative Infections Following Single Level Lumbar Fusion Surgery. Spine (Phila Pa 1976). 2014 Sep 29. [Epub ahead of print] 25. Fei Q, Li J, Lin J, Li D, Wang B, Meng H, Wang Q, Su N, Yang Y. Risk factors for surgical site infection following spinal surgery: A meta-analysis. World Neurosurg. 2015 Jun 5. pii: S1878-8750(15)00656-7. doi: 10.1016/j.wneu.2015.05.059. [Epub ahead of print]

\section{Disclosures}

No author has any conflicts of interest; the trial from which the data was derived received no funding by any external funding source.

\section{Corresponding Author}

Shearwood McClelland III, M.D. Spine Research Institute NYU Hospital for Joint Diseases, Department of Orthopaedic Surgery 306 East 15th Street, Ground Floor New York, NY 10003. drwood@post.harvard.edu

Published 21 April 2016.

This manuscript is generously published free of charge by ISASS, the International Society for the Advancement of Spine Surgery. Copyright ๑ 2016 ISASS. To see more or order reprints or permissions, see http://ijssurgery.com. 